\title{
METHOD AND APPARATUS FOR THE RAPID CONVERSION OF DEUTERIUM OXIDE INTO DEUTERIUM ${ }^{1}$
}

\author{
By John W. Knowlton and Frederick D. Rossini
}

\begin{abstract}
A method and apparatus are described in detail for the rapid conversion of deuterium oxide into deuterium. A glass bulb at one end of the evacuated conversion apparatus contains a sealed ampoule holding the liquid deuterium oxide. This ampoule of deuterium oxide is broken by placing liquid air around the outer bulb, which is subsequently heated electrically to control the passage of the vapors of deuterium oxide into the reaction tube containing powdered magnesium at $480^{\circ} \mathrm{C}$, where the following reaction occurs: $\mathrm{Mg}$ (solid) $+\mathrm{D}_{2} \mathrm{O}$ (gas) $=\mathrm{MgO}$ (solid) $+\mathrm{D}_{2}$ (gas). The rate of evolution of deuterium from the 1 -inch reaction tube can be made as great as 1 mole in 2 hours. The evolved deuterium passes through a liquid-air filter-trap and is collected as liquid in a $50-\mathrm{ml}$ brass bottle immersed in ordinary liquid hydrogen (temperature about $\left.-253^{\circ} \mathrm{C}\right)$. The connection to the conversion apparatus is closed, that to a 1-liter brass bottle is opened, and the deuterium is permitted to vaporize and fill the two brass bottles at room temperature. In this manner 95 percent of the deuterium is obtained in the 1-liter bottle as a gas under a pressure of about 23 atmospheres.
\end{abstract}

I. Introduction

II. Discussion of the reaction

III. Description of the apparatus

IV. Method of operation 609

V. Experimental results and conclusions

VI. References........... 612

\section{INTRODUCTION}

In connection with an investigation of the heat of formation of deuterium oxide, it was necessary to devise a method and apparatus for rapidly converting 1 mole of deuterium oxide into deuterium, and obtain the latter as a gas under pressure in a metal bottle. ${ }^{2}$

The process selected for the conversion of the deuterium oxide into deuterium had to be one which would be relatively rapid as well as complete, because of the necessity, as will be explained later, of condensing the deuterium to liquid as fast as it would be formed, by cooling with liquid hydrogen. It was estimated that, with the re-

\footnotetext{
1 The work described in this paper has been submitted by John W. Knowlton to the Graduate School of the University of Maryland in partial fulfillment of the requirements for the degree of Master of Science.

2 One gram-mole of pure deuterium oxide was very generously provided for this investigation by Prof. H. L. Johnston, of the Ohio State University. Once obtained as a pure gas, the deuterium could then be made to react with oxygen in a reaction vessel in a calorimeter in the determination of the heat of formation of deuterium oxide.
} 
frigerating facilities available, the $20 \mathrm{~g}$ of deuterium oxide would need to be completely decomposed in about 4 hours. This latter requirement, as well as the question of the probable presence of undesirable side reactions, eliminated the use, for the present investigation, of the classical process of electrolysis. The next obvious method wbich

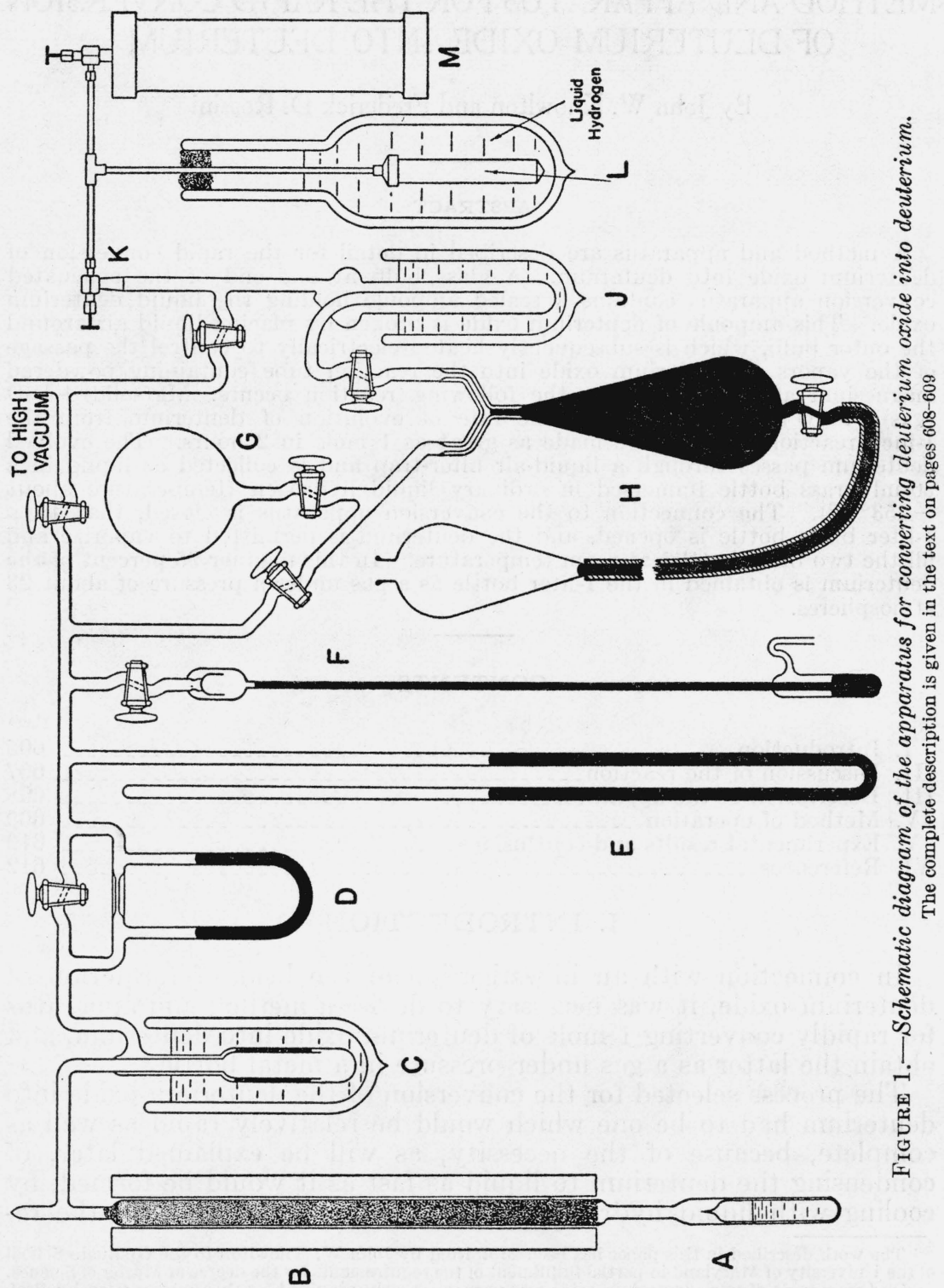

suggested itself was the reaction of the deuterium oxide with a metal to form the metallic oxide and deuterium. The metal would have to be one whose hydride and hydroxide are unstable at the temperature of the reaction. 
Zinc dust at $400^{\circ} \mathrm{C}$ was used successfully by Claussen and Hildebrand $[1]^{3}$ in connection with the preparation of small amounts of deuterium, but, in their work, the speed and completeness of the conversion were not important. In a preliminary experiment in this laboratory, it was found that, with a reaction tube similar to that shown at $B$ in figure 1 , and with water vapor passing into the reaction tube at the rate of about 1 mole in 4 hours, zinc powder at about $400^{\circ} \mathrm{C}$ permitted an appreciable amount of water vapor to pass undecomposed through the reaction zone. With the present apparatus, it was impractical to obtain a greater speed of reaction with zinc by elevating the temperature because of the proximity to the melting point of zinc, $419^{\circ} \mathrm{C}$.

Magnesium appeared to be the most promising metal to try next, because of its higher melting point, $650^{\circ} \mathrm{C}$, because its hydroxide is unstable at these elevated temperatures, and because it can be obtained in a state of high purity. In a preliminary experiment with the reaction tube shown in figure 1 , it was found that with water vapor passing into the reaction zone at the rate of about 1 mole in 4 hours, magnesium powder at $475^{\circ} \mathrm{C}$ reacted quantitatively with all the water entering the reaction zone. No water was collected in the liquid-air trap, $C$ in figure 1, during the decomposition of 1 mole of water, which indicates that no water passed undecomposed through the reaction tube.

\section{DISCUSSION OF THE REACTION}

The reactions which may occur in the reaction tube at $480^{\circ} \mathrm{C}$ under the conditions of the experiment include the desired reaction

$$
\mathrm{Mg} \text { (solid) }+\mathrm{H}_{2} \mathrm{O} \text { (gas) }=\mathrm{MgO} \text { (solid) }+\mathrm{H}_{2} \text { (gas), }
$$

and possible side reactions which might lead to the formation of the following substances: Magnesium hydroxide, magnesium hydride and magnesium silicide.

The free-energy data on magnesium hydroxide and magnesium oxide recently obtained by Giauque and Archibald [2] indicate definitely that the hydroxide is quite unstable at $480^{\circ} \mathrm{C}$. With regard to magnesium hydride, there is no definite evidence for its existence [3], but, reasoning by analogy from the high dissociation pressures found for sodium and potassium hydrides by Keyes [4], it may safely be concluded that such a hydride would decompose completely into magnesium and hydrogen at $480^{\circ} \mathrm{C}$ and at a low pressure of hydrogen. Mellor [3] reports the following: molten magnesium will attack glass, forming a film of oxide on the metal; silicon dioxide is reduced by magnesium when heated, forming silicon, magnesium oxide, and some magnesium silicide; boric oxide is also reduced by magnesium, forming boron and magnesium boride. It was actually observed, in the present experiments, that some magnesium silicide was formed at the wall of the Pyrex-glass reaction tube. Compounds such as silane are known to be quite unstable at $480^{\circ} \mathrm{C}$ [3].

Consideration of these possible side reactions indicates that they neither consume hydrogen nor form gaseous products. From the standpoint of the conversion of water into hydrogen, then, it appears that the process occurring in the reaction tube, under the conditions of these experiments, is a substantially pure one, as represented by

3 The numbers in brackets here and throughout the text refer to the references at the end of the paper. 
reaction (1), and that, therefore, this process would be satisfactory for the analogous reaction

$$
\mathrm{Mg} \text { (solid) }+\mathrm{D}_{2} \mathrm{O} \text { (gas) }=\mathrm{MgO} \text { (solid) }+\mathrm{D}_{2} \text { (gas) }
$$

\section{DESCRIPTION OF THE APPARATUS}

Figure 1 is a schematic diagram of the apparatus, all of which is made of Pyrex glass, with the exception of the metal parts $K, L$, and $M$. An ampoule of the deuterium oxide is contained in the bulb $A$. $B$ is the reaction tube, containing a graded charge of magnesium powder. This tube is inclosed in an electrical resistance furnace, which maintains the desired reaction temperature of about $480^{\circ} \mathrm{C}$. The reaction tube is connected with a liquid-air trap, $C$, packed with a filter of glass wool. A mercury flowmeter, $D$, provided with a bypassing stopcock, is inserted in the line; $E$ is a mercury manometer; and $F$ a safety outlet. A 1 -liter storage flask, $G$, is by-connected with the gas line, and is joined to a mercury-displacement gas-transferring apparatus, $H$. Through a second liquid-air trap, $J$, the gas-transferring apparatus is connected with the metal part of the system at $K$, by means of a glass-to-metal tapered joint sealed with Pizein wax. Also at $K$ there is a vacuum-tight needle valve connecting the glassto-metal joint with the condensing bulb, $L$, which is immersed in liquid hydrogen during the reaction. The condensing bulb is connected with a 1-liter cylindrical brass bomb, $M$, fitted with a needle valve.

The sample of deuterium oxide is sealed off in a glass ampoule and placed in the bulb, $A$, in order that the whole system may be evacuated. When it is desired to begin the experiment, the ampoule is broken by rapid freezing in liquid air. Several trial experiments showed that this can be done without danger of breaking the outer bulb. The use of a slush composed of solid carbon dioxide, carbon tetrachloride, and chloroform is not completely satisfactory for breaking the watercontaining bulb in this manner, because of the slower rate of freezing. In order to vaporize the deuterium oxide and cause it to pass into the reaction zone, a small tubular furnace (not shown in fig. 1) is slipped over the bulb $A$, after the ampoule is broken.

A charge of magnesium powder of graded fineness is placed in the reaction tube, $B$. A preliminary experiment showed that when the magnesium powder in the lower end of the reaction tube is too fine, the reaction is so complete at the entrance end of the tube that the magnesium oxide formed offers too much resistance to the flow of water vapor through it. The use of a charge consisting of coarse granules of magnesium at the lower (entrance) end of the reaction tube, grading to a fine powder at the upper (exit) end, was found to work satisfactorily. Two pounds each of magnesium turnings, labeled "10 mesh and finer", and " 35 to 48 mesh", were sifted on nos. 12-, 20-, 30-, and 42-mesh sieves. ${ }^{4}$ Of this material, a negligible amount was retained by the 12 -mesh sieve; $19 \mathrm{~g}$ by the 20 -mesh; $382 \mathrm{~g}$ by the 30 -mesh; and $1,191 \mathrm{~g}$ by the 42 -mesh sieve. This magnesium was obtained from the American Magnesium Corporation, Cleveland, Ohio, and contained as impurities 0.10 percent of magnesium oxide, 0.03 percent of aluminum plus iron, 0.002 percent of silicon, and no zinc, lead, or copper. The reaction tube, which has an internal diameter of $2.4 \mathrm{~cm}$

\footnotetext{
- These sizes of mesh refer to the Tyler Standard Screen Scale and give the meshes per inch.
} 
and a length of $55 \mathrm{~cm}$, is filled with $10 \mathrm{~g}$ of " 20 mesh", $30 \mathrm{~g}$ of "30 mesh", $50 \mathrm{~g}$ of " 42 mesh", and $40 \mathrm{~g}$ of " $<42$ mesh" magnesium powder, or $130 \mathrm{~g}$ in all. This is 5.3 times the theoretical amount and completely fills the tube to its upper constriction. The charge is supported by a perforated platinum disk held in place by glass shoulders sealed on the wall of the reaction tube. A small plug of glass cotton is placed over the fine magnesium powder at the top of the charge to hold it in position while the reaction proceeds.

The filter trap, $C$, cooled with liquid air, is similar to a filtering arrangement described by Shepherd [5], and is used to retain any possible unreacted water vapor passing through the reaction zone. In the preliminary experiments with ordinary water, as well as in the conversion of the deuterium oxide, no water was condensed in this trap.

The flowmeter, $D$, is used as a measure of the speed of the reaction in order that the conditions can be adjusted so that the process will be complete within the desired time. A calibration of the flowmeter was obtained for hydrogen, and this was converted into terms of the rate of flow of deuterium by means of the factor $1 / 1.41$, the ratio of the viscosity of hydrogen to that of deuterium [6]. A by-passing stopcock is provided on the flowmeter to facilitate the evacuation of the system. During the reaction this stopcock is normally closed.

While the reaction is in progress, the manometer, $E$, measures the pressure of the system at this point. The outlet, $F$, is provided as a safety measure.

On completion of the reaction, the residual deuterium in the system is pumped into the condensing bulb, $L$, by means of the gas-transferring apparatus, $H$. The function of the liquid-air trap, $J$, is to remove mercury vapor from the gas passing into the metal part of the system.

The metal connecting tubes, used beyond the point $K$, are made of copper-nickel alloy of low heat conductivity, composed of 80 percent of copper and 20 percent of nickel. The condensing bulb, $L$, of $50-\mathrm{ml}$ capacity, is constructed of brass.

For use in the investigation of the heat of formation of deuterium oxide, it is necessary to have the deuterium produced by this method confined under pressure, so that the gas can be readily delivered to the reaction vessel in the calorimeter. The cylindrical brass bomb, $M$, of 1-liter capacity, fitted with a needle valve, is provided for this purpose.

\section{METHOD OF OPERATION}

The method of operation consists in evacuating the entire system, breaking the ampoule of deuterium oxide, passing its vapor through the hot magnesium powder, and collecting the effluent deuterium gas by liquefying it in the condensing bulb. Subsequent vaporization of the deuterium fills the bomb with the pure gas, where it is stored under pressure.

After the ampoule of deuterium oxide is sealed into the bulb, $A$, and the charge of magnesium is introduced, the filling tube at the top of the reaction tube, $B$, is sealed off, and the side arm of the reaction tube is joined to the rest of the system. The whole apparatus is then evacuated, and the reaction tube is gradually heated to $500^{\circ} \mathrm{C}$, while the evacuation is continued, until a pressure of about $10^{-4} \mathrm{~mm}$ (measured on a McLeod gage attached to the mercury diffusion pump 
and backed by a liquid-air trap) is maintained overnight with the system closed off from the pump. The two connections to the vacuum line and the by-passing stopcock on the flowmeter, $D$, facilitate this pumping operation.

When the vacuum is found to hold in the system, the apparatus is ready for the reaction. The stopcocks leading to the vacuum pump and by-passing the flowmeter, $D$, are closed, and the furnace around the reaction tube, $B$, is heated to about $480^{\circ} \mathrm{C}$. Liquid air is placed around the traps, $C$, and $J$. The condensing bulb, $L$, after being cooled with liquid air, is submerged in liquid hydrogen. The level of the mercury in the gas-transferring apparatus, $H$, is adjusted to a point just below the constriction on the reservoir, as shown in figure 1, and kept in this position all through the actual conversion.

When the furnace has reached a temperature of about $480^{\circ} \mathrm{C}$, the ampoule of deuterium oxide in the bulb, $A$, is broken by rapid freezing with liquid air. Since the speed of the reaction is governed by the rate at which the vapor of deuterium oxide is delivered to the reaction tube, a short tubular furnace is now slipped over the water bulb, $A$, and it is heated until the reaction attains the desired rate, as measured on the flowmeter, $D$.

When the reaction is once under way, the pressure of the system rises to about $\frac{1}{3}$ atmosphere, the vapor pressure of deuterium at the normal boiling point of hydrogen [7]. Readings of the pressure, as measured by the manometer, $E$, are taken at intervals throughout the experiment in order to be certain that the deuterium is being liquefied as rapidly as it is being formed. At the same time, a record is made of the rate of passage of the deuterium through the flowmeter, and of the temperatures of the reaction tube and the water bulb, to insure the maintenance of the proper conditions for the experiment.

The completion of the reaction is marked by a rapid falling off to practically zero of the rate of evolution of the deuterium. This may be checked by removing the small furnace from the water bulb, $A$, to ascertain whether all the deuterium oxide has been vaporized. The furnace is then replaced and heated to well above the boiling point of the deuterium oxide in order to drive out any last traces of the deuterium oxide.

The residual deuterium in the system is now pumped into the condensing bulb, $L$, by displacement of the mercury in the gas-transferring apparatus, $H$, and manipulation of the stopcocks leading to it. The valve, $K$, is closed, the liquid hydrogen is removed from $L$, and the deuterium is vaporized, filling the bomb, $M$, and the bulb, $L$. Then the valve on the bomb is closed, and the deuterium remaining in the condensing bulb (about $50 \mathrm{ml}$ at a pressure of 23 atmospheres) is released back into the gas-transferring apparatus, and forced into the reservoir flask, $G$, where it is stored. By means of these operations, a minimum amount of deuterium is lost when the bomb is disconnected.

\section{EXPERIMENTAL RESULTS AND CONCLUSIONS}

In an actual experiment, in which $19.5 \mathrm{~g}$ of deuterium oxide was converted to the corresponding amount of deuterium, the data shown in table 1 were obtained. It had been planned to complete the entire reaction in about 4 hours, but it was found possible to decrease this 
period considerably. The actual evolution of 1 mole of gaseous deuterium required slightly more than 2 hours, the gas flowing at about $600 \mathrm{ml}$ per minute at a pressure of about $1 / 3$ atmosphere. The rate of the conversion was controlled by the rate of input of energy into the bulb containing the liquid $\mathrm{D}_{2} \mathrm{O}$. From the data given in table 1 , it appears that the vapor pressure of the deuterium oxide was somewhat above 1 atmosphere [8]. The pressure drop through the reaction tube ( $B$ in fig. 1) was, therefore, a little greater than $2 / 3$ atmosphere. It is possible that an even greater speed of conversion could be satisfactorily used by operating with a greater pressure in the deuterium-oxide side of the reaction tube, obtained by appropriately increasing the temperature of the bulb containing the deuterium oxide.

TABLE 1.-Experimental data from one conversion

\begin{tabular}{|c|c|c|c|c|c|}
\hline $\begin{array}{c}\text { Time } \\
\text { (hr. min.) }\end{array}$ & $\begin{array}{l}\text { Temper- } \\
\text { ature of } \\
\text { reaction } \\
\text { tube }\end{array}$ & $\begin{array}{c}\text { Temper- } \\
\text { ature of } \\
\mathrm{D}_{2} \mathrm{O} \\
\text { bulb b }\end{array}$ & $\begin{array}{c}\text { Rate of } \\
\text { flow of } \\
\mathrm{D}_{2}\end{array}$ & $\begin{array}{l}\text { Pressure of } \\
\mathrm{D}_{\mathbf{2}} \text { in system }\end{array}$ & Remarks \\
\hline $\begin{array}{l}0: 00 \\
0: 03\end{array}$ & ${ }^{\circ} \mathrm{C}$ & ${ }^{\circ} \mathrm{O}$ & $\mathrm{ml} / \mathrm{min}$ & $\mathrm{mm} \mathrm{Hg}$ & \multirow{7}{*}{$\begin{array}{l}\text { Liquid air placed on } \mathrm{D}_{2} \mathrm{O} \text { bulb. } \\
\mathrm{D}_{2} \mathrm{O} \text { bulb cracked and ice melted. } \\
\mathrm{Small}_{\text {furnace placed around } \mathrm{D}_{\mathbf{2}} \mathrm{O} \text { bulb. }} \text { Pressure rising. } \\
\text { Pressure appears to be constant. } \\
\text { Remaved furnace from } \mathrm{D}_{2} \mathrm{O} \text { bulb and noted } \\
\text { quiet boiling of liquid. } \\
\text { Effect of foregoing interruption. }\end{array}$} \\
\hline $0: 45$ & 485 & 76 & 363 & \multirow{2}{*}{$\begin{array}{r}67 \\
250 \\
270\end{array}$} & \\
\hline $\begin{array}{l}1: 00 \\
1: 01\end{array}$ & 483 & & 343 & & \\
\hline 1:03 & & & & & \\
\hline $\begin{array}{l}1: 10 \\
1: 20\end{array}$ & $\begin{array}{l}488 \\
483\end{array}$ & 104 & 655 & \multirow{2}{*}{$\begin{array}{l}268 \\
264 \\
264 \\
\end{array}$} & \\
\hline $1: 26$ & & & & & \\
\hline $1: 28$ & 483 & 104 & 405 & 261 & \\
\hline $1: 38$ & 480 & 108 & 634 & & \multirow{8}{*}{ Rate visibly dropping. } \\
\hline $1: 50$ & 485 & 103 & 655 & 262 & \\
\hline & 485 & 105 & 780 & 264 & \\
\hline $\begin{array}{l}2: 10 \\
2: 20\end{array}$ & $\begin{array}{l}485 \\
488\end{array}$ & $\begin{array}{l}103 \\
103\end{array}$ & $\begin{array}{l}780 \\
780\end{array}$ & $\begin{array}{l}264 \\
264\end{array}$ & \\
\hline $2: 30$ & 494 & 108 & 770 & \multirow{3}{*}{$\begin{array}{l}264 \\
263\end{array}$} & \\
\hline $2: 40$ & 494 & 110 & 593 & & \\
\hline $\begin{array}{l}2: 43 \\
0 \cdot 44\end{array}$ & & $\cdots$ & 291 & & \\
\hline $\begin{array}{l}2.44 \\
2: 47\end{array}$ & & & $\begin{array}{r}190 \\
62\end{array}$ & 260 & \\
\hline $2: 54$ & 494 & 141 & 10 & 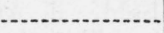 & \multirow[b]{2}{*}{$\begin{array}{l}\text { Valve on condensing bulb closed off. Baro } \\
\text { metric pressure } 757 \mathrm{~mm} \text { (corrected). }\end{array}$} \\
\hline $3: 02$ & & & & & \\
\hline
\end{tabular}

- These temperatures are accurate to about $\pm 5^{\circ} \mathrm{C}$.

- These temperatures are accurate to about $\pm 3^{\circ} \mathrm{C}$.

The remaining point of interest in connection with this method of converting deuterium oxide into deuterium concerns the possible introduction of hydrogen atoms to either the deuterium oxide or the deuterium in the course of the work. It appears that the deuterium oxide available for the present investigation had as an impurity hydrogen atoms to the extent of about 0.01 atomic percent. (See reference [9] for a detailed discussion of the composition.) Prior to the conversion, the $19.5 \mathrm{-g}$ sample was subjected to a threefold distillation in vacuum and was sealed in a Pyrex-glass ampoule. An analysis of the gaseous deuterium collected in the 1-liter cylindrical brass bomb ( $M$, in fig. 1 ) was made by F. G. Brickwedde and R. B. Scott (see reference [9] for details), who measured the vapor pressure of the liquefied deuterium against that of normal or natural hydrogen in the liquid state. These data on vapor pressure indicate that the gaseous deuterium produced had as impurity hydrogen atoms to the 
extent of 0.73 percent of the total number of hydrogen and deuterium atoms (corresponding to the actual presence of 1.45 percent of HD), referred to the sample of deuterium measured by Brickwedde, Scott, and Taylor [7], as being 100.00 percent.

It is apparent that this additional impurity of about 0.7 percent of hydrogen atoms was introduced in the conversion experiment either by exchange with the glass and metal walls, or from the magnesium powder. Some exchange may have also occurred during the preliminary distillation of the deuterium oxide. Thehydrogen atoms introduced by exchange with the glass and metal walls would not be expected to be a large fraction of impurity, because of the large amount (1 mole) of gas converted. In any subsequent experiment with this method of conversion, the impurity of hydrogen atoms introduced in this way can be largely reduced by first "flushing" all the glass and metal surfaces and the magnesium powder with a small amount of deuterium gas, produced at the beginning of the conversion, and then discharging this impure gas from the system before beginning the formal collection of the deuterium.

The authors are greatly indebted to Prof. H. L. Johnston, Department of Chemistry, Ohio State University, for placing $19.5 \mathrm{~g}$ of pure deuterium oxide at their disposal; to Martin Shepherd, of this Bureau, for his advice during the course of the present investigation, and for the loan of the metal vessels used for condensing and storing the deuterium; to J. W. Cook, of this Bureau, for manipulating the liquid hydrogen during the experiment; to F. G. Brickwedde and R. B. Scott, of this Bureau, for analyzing the deuterium produced; and to Prof. M. M. Haring, Department of Chemistry, University of Maryland, for his kind interest in the problem.

\section{REFERENCES}

[1]. W. H. Claussen and J. H. Hildebrand. J. Am. Chem. Soc. 56, 1820 (1934).

[2]. W. F. Giauque and R. C. Archibald. J. Am. Chem. Soc. 59, 561 (1937).

[3]. J. W. Mellor. A Comprehensive Treatise on Inorganic and Theoretical Chemistry 4, 266, 271, 272; 6, 147, 160, 216, 218, 219, 222 (Longmans, Green, and Co., London, 1922).

[4]. F. G. Keyes. J. Am. Chem. Soc. 34, 779 (1912).

[5]. Martin Shepherd. BS J. Research 2, 1145 (1929) RP75.

[6]. H. C. Torrey. Phys. Rev. 4\%, 644 (1935).

[7]. F. G. Brickwedde. R. B. Scott, and H. S. Taylor. J. Research NBS 15 463 (1935) RP841.

[8]. F. T. Miles and A. W. C. Menzies. J. Am. Chem. Soc. 58, 1067 (1936).

[9]. F. D. Rossini and J. W. Knowlton. Forthcoming publication in J. Resear NBS.

Washington, October 5, 1937. 